Proceedings

\title{
Determination of Undesirable Volatile Organic Compounds in Petroleum Derivative Products by Thermal Desorption and Gas Chromatography - Mass Spectrometry Technique
}

\author{
Marta Barea-Sepúlveda *, Marta Ferreiro-González and Miguel Palma
}

Department of Analytical Chemistry, Faculty of Sciences, University of Cadiz, Agri-food Campus of International Excellence (ceiA3), IVAGRO, 11510 Puerto Real, Cadiz, Spain; marta.ferreiro@uca.es (M.F.-G.); miguel.palma@uca.es (M.P.)

* Correspondence: marta.barea@uca.es (M.B.-S.)

Publisher's Note: MDPI stays neutral with regard to jurisdictional claims in published maps and institutional affiliations.

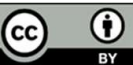

Copyright: () 2020 by the authors. Submitted for possible open access publication under the terms and conditions of the Creative Commons Attribution (CC BY) license (http://creativecommons.org/licenses/by/4.0/).

\begin{abstract}
Petroleum remains the principal raw material for the manufacture of a wide variety of products with multiple uses. Within this framework, it is possible to find petroleum derivative products, such as paraffin waxes, with applications in the agri-food industry. Due to the above-mentioned use, the adaptation of the quality control of these products to the requirements of this industry is a factor to be considered by the producers to comply with food safety standards. The present study is focused on establishing the starting conditions for the development and optimization of an analytical methodology based on TD-GC-MS (Thermal Desorption - Gas Chromatography - Mass Spectrometry) that allows the determination and identification of the volatile organic compounds (VOCs) that are undesirable not only because of their smell but also because they may pose a risk to health as a result of prolonged exposure. Desorption temperature, as well as the chromatographic separation conditions, were studied to determine VOCs related to paraffin waxes in food packaging materials used by food industries.
\end{abstract}

Keywords: paraffin wax; food-packaging; volatile organic compounds; thermal desorption; GC-MS

\section{Introduction}

Petroleum derivative products (PDPs) are essential for manufacturing a wide range of products with multiple applications in different fields. Among PDPs' numerous usages, it is possible to find some of them in the agri-food sector, concretely as food-packaging material such as paraffin waxes, used to preserve the humidity and slow down the deterioration of some cheeses, for example [1].

Generically, paraffin wax can be defined as a solid wax at room temperature that is obtained in the refining of lubricating oils. In addition to the use mentioned above, paraffin waxes are used in the manufacture of a wide variety of products, being the most wellknown use in the manufacture of candles [2]. In recent years, consumers have become increasingly demanding concerning food quality due to a greater degree of knowledge about biotic and abiotic contaminants and their direct consequences on health. For this reason, companies in charge of manufacturing and distributing paraffin waxes for foodpackaging applications must have quality control programs to ensure compliance with safety and hygiene standards in their products. In that way, food-grade paraffin waxes are subjected to a process of hydrotreatment at high pressure and temperature [1,3] to meet the requirements of the U.S. Food and Drug Administration (FDA) 21 CFR 172.886 [4] for their use in food and 21 CFR 178.371 [5] for direct contact with food.

One of the principal parameters to be evaluated in quality control is the smell. Firstly, because paraffin waxes with applications in the agri-food industry must be odorless to avoid interaction with the overall aroma of the food and, on the other hand, to prevent 
aroma-producing compounds from being transferred to the product [2,6]. Paraffin waxes aromatic and volatile profile was studied by Men et al. (2018) by using the global profile technique Headspace Electronic Nose (HS eNose) [6]. Nevertheless, global profile techniques only provide overall information on samples' volatile composition [7].

It is interesting to study which VOCs are present in paraffin waxes because they could be transferred to the food during food processing and storage. Besides, individual identification of VOCs is important in assessing possible health risks from consumption and/or prolonged exposure to these compounds. Therefore, the present work is focused on establishing the heating temperature and time in the thermal desorption unit, as well as the chromatographic separation conditions, for the development of an analytical methodology based on TD-GC-MS (Thermal Desorption-Gas Chromatography-Mass Spectrometry) that allows the characterization of VOCs in paraffin-based packaging. This type of analysis avoids sample handling and it reduces the waste generation. To the best of our knowledge, this is the first time that TD-GC-MS has been applied on the analysis of VOCs from in paraffin-based packaging for foods.

\section{Materials and Methods}

\subsection{Paraffin-based Packaging Samples}

Different kinds of red paraffin-based used for food-packaging were purchased at local markets available to consumers in Spain. Specifically, cheese and cheese for children paraffin-based packaging were used in this study. Before the analysis, each sample was wrapped in aluminum foil and stored individually in an odorless glass container, perfectly sealed and labeled.

\subsection{Analysis of VOCs in Paraffin-based Packaging by TD-GC-MS}

The analysis of VOCs of paraffin-based packaging samples were carried out by the TD-GC-MS technique. An amount of $1.5 \mathrm{mg}$ of each sample was placed together with glass wool in an empty glass sample tube for thermal desorption of length $90 \mathrm{~mm}$ and outer diameter 1/4" (Shimadzu Scientific Instruments, Kyoto, Japan). No organic solvent is required in sample preparation, so the thermal desorption was done directly on the paraffinbased packaging. Sample tubes were thermally desorbed by an automated thermal desorption unit (TD-20; Shimadzu Scientific Instruments, Kyoto, Japan) coupled to a gas chromatograph with a triple quadrupole (Q3) mass spectrometry detector (GC-MS TQ8040; Shimadzu Scientific Instruments, Kyoto, Japan).

\subsubsection{TD-GC-MS Conditions}

Thermal desorption of sample tubes was performed in a two-step mode. Firstly, the sample tube was heated to $80{ }^{\circ} \mathrm{C}$ for $10 \mathrm{~min}$. VOCs were desorbed in a flow rate of 60 $\mathrm{mL} / \mathrm{min}$ of $\mathrm{He}\left(5 \mathrm{~N}\right.$ grade) and collected into a 50-60 mg Tenax ${ }^{\mathrm{TM}} \mathrm{TA}$ cryogenic trap, cooled at $-15{ }^{\circ} \mathrm{C}$. In the second step, trap desorption was carried out at $280{ }^{\circ} \mathrm{C}$ for $3 \mathrm{~min}$, and desorbed VOCs were transferred (split 1:50) to a Silicosteel ${ }^{\circledR}$ transfer line heated to 250 ${ }^{\circ} \mathrm{C}$. The transfer line introduced the VOCs into the GC-MS system. The GC was equipped with a BPX5 capillary column (length $30 \mathrm{~m}$; internal diameter $0.25 \mathrm{~mm}$; film thickness 0.25 $\mu \mathrm{m}$; SGE ${ }^{\mathrm{TM}}$ Analytical Science, Melrose Park, NSW, Australia). Helium (5N grades) was the carrier gas at a linear velocity flow mode of $0.94 \mathrm{~mL} / \mathrm{min}$. The GC oven temperature program for VOCs analysis started a $40{ }^{\circ} \mathrm{C}$ (holding time $5 \mathrm{~min}$ ) then it increased to 220 ${ }^{\circ} \mathrm{C}$ at $3{ }^{\circ} \mathrm{C} / \mathrm{min}$ (holding time $15 \mathrm{~min}$ ) and to $270{ }^{\circ} \mathrm{C}$ at $40{ }^{\circ} \mathrm{C} / \mathrm{min}$ (holding time $2 \mathrm{~min}$ ). The MS ion source and interface temperatures were $200{ }^{\circ} \mathrm{C}$ and $275^{\circ} \mathrm{C}$, respectively. On the other hand, electron ionization at $70 \mathrm{eV}$ was the ionization mode, and MS was run in a Q3 Scan mode within a 50-600 $\mathrm{m} / \mathrm{z}$ range. 


\subsection{VOCs Identification}

VOCs were identified by comparing the mass spectrum from each chromatographic peak with the mass spectrum of the compounds in the NIST 2014 library version (National Institute of Standards and Technology, Gaithersburg, MD, USA). Furthermore, a saturated alkanes standard $\left(\mathrm{C}_{7}-\mathrm{C}_{40}\right.$; Sigma-Aldrich, St. Louis, MO, USA) was analyzed using the same method to calculate the retention index to identify the VOCs by comparison with the NIST library or literature.

\section{Results and Discussion}

\subsection{Sample Heating Temperature}

Heating temperature and time are important variables since they determine the content of VOCs desorbed from the sample, then transferred from the sample to the Tenax ${ }^{\mathrm{TM}}$ TA cryogenic trap. No references related to the determination of VOCs in paraffin-based packaging materials by TD-GC-MS were found in the literature. Thus, the heating temperature was evaluated to achieve the right conditions for the determination of VOCs in the samples. The following sample heating temperatures were investigated: $80^{\circ} \mathrm{C}, 100{ }^{\circ} \mathrm{C}$, and $150{ }^{\circ} \mathrm{C}$. On the other hand, the sample heating time was set at $10 \mathrm{~min}$. The results obtained indicated that the sample heating temperature directly affects the peak area and along with the absolute intensity. The heating temperature clearly conditioned the resulting chromatograms. More intense chromatographic peaks were obtained at the highest temperature, however no additional compounds were detected using higher temperatures. Therefore, $80^{\circ} \mathrm{C}$ was selected as the initial sample heating temperature to guarantee the integrity of VOCs.

\subsection{Identification of VOCs in Paraffin-based Packaging}

More than 30 VOCs were detected in the samples from the packaging materials from both cheese and cheese for children paraffin-based packaging. A total of 10 compounds were selected either because they are present in pure paraffin wax or because they are relevant from a food safety point of view. Table 1 shows identified VOCs by using retention index, MS library matching criteria and comparing the chromatographic and mass spectra with commercial standards.

Table 1. List of identified compounds in cheese and cheese for children paraffin-based with their corresponding chemical family group, identifier (ID), retention time (RT), calculated retention index (Calc I), and theoretical retention index (Lit I). .

\begin{tabular}{|c|c|c|c|c|c|c|c|}
\hline \multirow[b]{2}{*}{ Family } & \multirow[b]{2}{*}{ ID } & \multirow[b]{2}{*}{ Compound } & \multicolumn{2}{|c|}{$\begin{array}{c}\text { Cheese paraffin- } \\
\text { based packing }\end{array}$} & \multicolumn{2}{|c|}{$\begin{array}{c}\text { Cheese for children } \\
\text { paraffin-based packing }\end{array}$} & \multirow[b]{2}{*}{ Lit I } \\
\hline & & & $\begin{array}{c}\text { RT } \\
\text { (min) }\end{array}$ & Calc I & $\begin{array}{c}\mathrm{RT} \\
\text { (min) }\end{array}$ & Calc I & \\
\hline Aldehydes & 1 & Nonanal & 21.943 & 1112 & n.d. 4 & n.d. ${ }^{4}$ & $1104^{5}$ \\
\hline n-Alkanes & 2 & Dodecane $^{1}$ & 26.290 & - & 26.270 & - & - \\
\hline n-Alkanes & 3 & Tridecane $^{1}$ & 31.009 & - & 30.990 & - & - \\
\hline n-Alkanes & 4 & Tetradecane ${ }^{1}$ & 35.456 & - & 25.432 & - & - \\
\hline n-Alkanes & 5 & Pentadecane ${ }^{1}$ & 39.641 & - & 39.613 & - & - \\
\hline $\begin{array}{l}\text { Phenol deriv- } \\
\text { atives }\end{array}$ & 6 & $\mathrm{BHT}^{2}$ & 39.986 & 1506 & 39.965 & 1504 & $1512^{6}$ \\
\hline n-Alkanes & 7 & Hexadecane 1 & 43.593 & - & 43.574 & - & - \\
\hline n-Alkanes & 8 & Heptadecane ${ }^{1}$ & 47.351 & - & 47.324 & - & - \\
\hline n-Alkanes & 9 & Octadecane ${ }^{1}$ & 50.931 & - & 50.894 & - & - \\
\hline Phthalates & 10 & $\mathrm{DBP}^{3}$ & n.d. ${ }^{4}$ & n.d. ${ }^{4}$ & 56.620 & 1900 & $1973^{7}$ \\
\hline
\end{tabular}

${ }^{1}$ Compound identified by comparison with commercially available standard. ${ }^{2}$ BHT - Butylated hydroxytoluene (2,6-ditert-butyl-4-methyphenol). ${ }^{3}$ DBP - Dibutyl phthalate. ${ }^{4}$ n.d. - Non detected. ${ }^{5}$ NIST Library (2014 versions). ${ }^{6}$ Kotowska, et al. (2012) [8]. ${ }^{7}$ Dickschat et al. (2004) [9]. 
As can be seen in Figure 1, the chromatographic profile between the studied paraffinbased packaging is very similar. Nevertheless, there are some differences, as the height and area of the chromatographic peaks. In general, it was observed that the most represented chemical family in both chromatograms is the $n$-alkanes group. Specifically, the $\mathrm{C}_{12}-\mathrm{C}_{18}$ alkanes were certainly identified in both samples. This result was within our expectations since paraffin waxes are solids of a complex mixture essentially constituted of paraffin hydrocarbons. On the other hand, BHT (butylated hydroxytoluene) was found in all the paraffin-based packaging samples. Undoubtedly, BHT is a widely used antioxidant in foods and food-related products, such as packaging. Thus, the exposure of society, as well as the environment, to this substance is likely to happen [10]. Although it has not been listed as a cancerogenic compound, there are many studies related to its negative effects on animal models [11,12]. Nonetheless, the information about BHT exposure in humans is limited. Currently, an ADI (Acceptable Daily Intake) of $0.25 \mathrm{mg} / \mathrm{kg}$ bw (body weight) was established by the EFSA (European Food Safety Authority) [13].

DBP (dibutyl phthalate) was also identified in cheese for children paraffin-based packaging. This substance is commonly used as a plasticizer in a great variety of consumer products. To date, no information is available regarding the effects of exposure to DBP on humans. Therefore, is not considered to be a carcinogen in human. Consequently, the EPA (U.S. Environmental Protection Agency) has classified this compound as a Group D (not classifiable as to human carcinogenicity) [14,15]. For its part, the EFSA has established a TDI (Tolerable Daily Intake) of $10 \mu \mathrm{g} / \mathrm{kg}$ bw for DBP [16]. Conversely, nonanal was detected in cheese paraffin-based packaging. Nonanal is a $C_{9}$ saturated fatty aldehyde characterized by a rose-orange odor. The JECFA (Joint FAO/WHO Expert Committee on Food Additives) established an ADI of $0-0.1 \mathrm{mg} / \mathrm{kg}$ bw for this substance and declared no safety concern at current levels of intake when used as a flavoring agent [17].

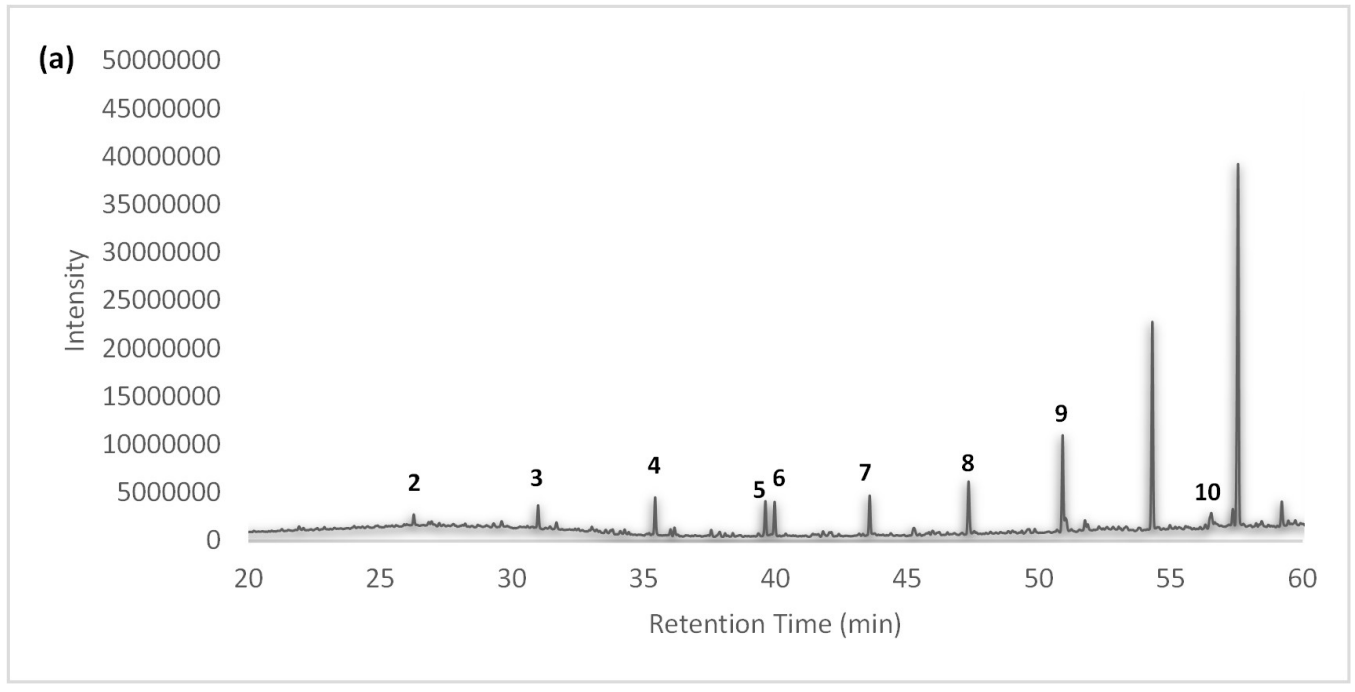




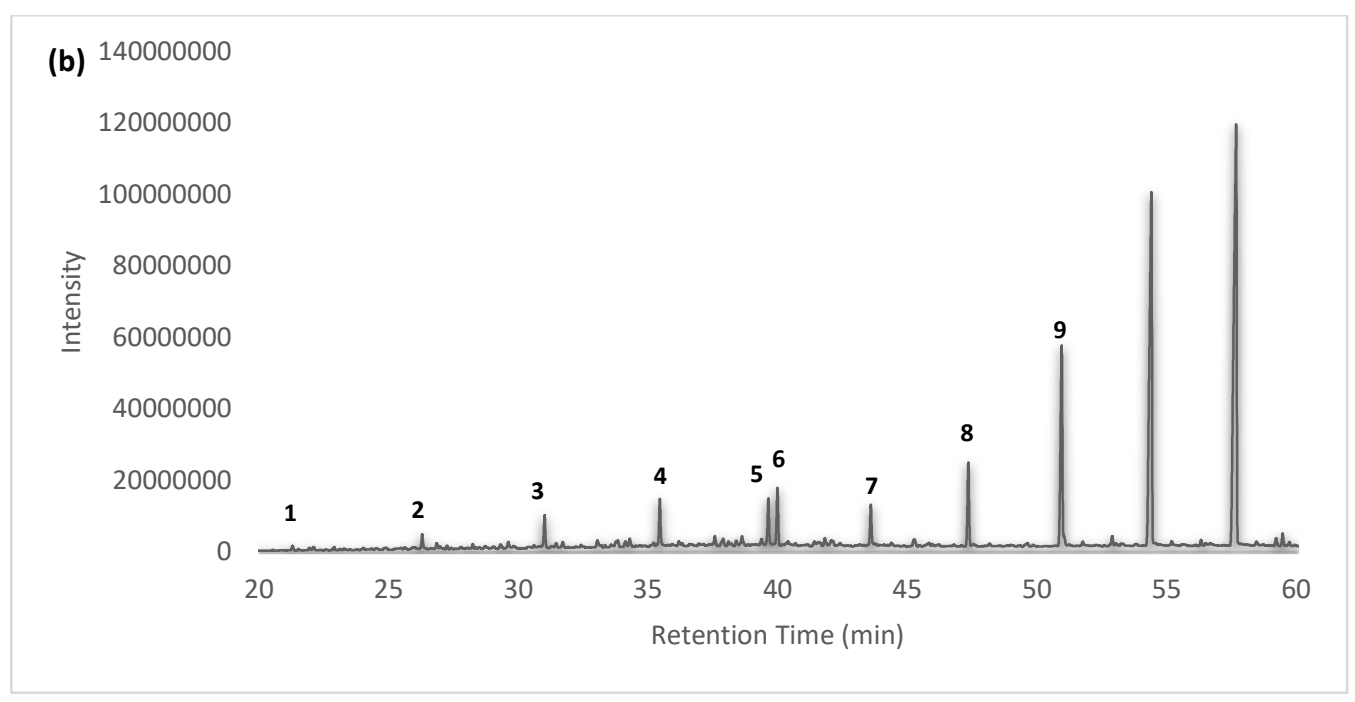

Figure 1. TD-GC-MS chromatograms: (a) Total Ion Chromatogram (TIC) of the cheese for children paraffin-based packaging; (b) Total Ion Chromatogram (TIC) of the cheese paraffin-based packaging. They key for the identified compounds is in Table 1.

\section{Conclusions}

The identification of 10 volatile organic compounds in different paraffin-based packing was performed. The $n$-alkanes were the most represented chemical family in the studied samples. The results obtained have demonstrated the sensitivity of the DT-GC-MS technique for the determination of VOCs in this type of sample. Furthermore, the established instrumental parameters have allowed obtaining a good chromatographic separation and grant the future quantification of the identified VOCs after the optimization and validation of this analytical method.

Author Contributions: M.B.-S., M.F.-G., and M.P. conceived and design the experiments, conceptualized the work, and prepared the manuscript for publication; M.B. conducted the methodology, validated, formal analyzed, and writing - original draft preparation; M.F. supervised, reviewed, and edited the manuscript; M.P., supervised, provided resources, reviewed, and edited the manuscript. All authors have read and agreed to the published version of the manuscript.

Funding: This research was financially supported by the University of Cadiz and the Cátedra Fundación CEPSA.

Acknowledgments: The authors thank the University of Cadiz and the Cátedra Fundación CEPSA for the predoctoral contract (FPI UCA/TDI-4-19) granted to Marta Barea-Sepúlveda.

Conflicts of Interest: The authors declare no conflict of interest.

\section{References}

[1] Sánchez, J.; Tallafigo, M.F.; Gilarranz, M.A.; Rodríguez, F. Catalytic hydrotreatment of crude waxes from different sources over a Ni-W/-Al2O3 catalyst. Ind. Eng. Chem. Res. 2008, 47, 6854-6861, doi: doi.org/10.1021/ie800014u.

[2] Speight, J.G. Hydrocarbons from Petroleum. In Handbook of Industrial Hydrocarbon Processes. Elsevier, Ed., Oxford. United Kingdom, 2011, 122 -125, doi: 10.1016/b978-0-7506-8632-7.10003-9.

[3] Ancheyta, J.; Rana, M.S.; Furimsky, E. Hydroprocessing of heavy petroleum feeds: Tutorial. Catal. Today 2005, 109, 3-15, doi: 10.1016/j.cattod.2005.08.025.

[4] U.S. Food and Drug Administration (FDA). Food additives permitted for direct addition to food for human consumption. Code of Federal Regulations; FDA: Silver Spring, MD, 2013; Part 172, Title 21, Vol. 3.

[5] U.S. Food and Drug Administration (FDA). Indirect food additives: Adjuvants, production aids, and sanitizers. Code of Federal Regulations; FDA: Silver Spring, MD, 2013; Part 178, Title 21, Vol. 3. (11).

[6] Men, H.; Fu, S.; Yang, J.; Cheng, M.; Shi, Y.; Liu, J. Comparison of SVM, RF and ELM on an Electronic Nose for the Intelligent Evaluation of Paraffin Samples. Sensors 2018, 18, 285, doi: 10.3390/s18010285. 
[7] Konieczka, P.P.; Aliaño-González, M.J.; Ferreiro-González. M.; Barbero, G.F.; Palma, M. Characterization of Arabica and Robusta coffees by ion mobility sum spectrum. Sensors 2020, 20, 3123, doi: 10.3390/s20113123.

[8] Kotowska, U.; Żalikowski, M.; Isidorov, V.A. HS-SPME/GC-MS analysis of volatile and semi-volatile organic compounds emitted from municipal sewage sludge. Environ. Monit. Assess 2012, 184, 2893-2907, doi: 10.1007/s10661-011-2158-8.

[9] Dickschat, J.S.; Wenzel, S.C.; Bode, H.B.; Müller, R.; Schulz, S. Biosynthesis of volatiles by the myxobacterium Myxococcus xanthus. ChemBioChem 2004, 5, 778-787, doi: 10.1002/cbic.200300813.

[10] Schmidtkunz, C.; Küpper, K.; Weber, T.; Leng, G.; Kolossa-Gehring, M. A biomonitoring study assessing the exposure of young German adults to butylated hydroxytoluene (BHT). Int. J. Hyg. Environ. Health 2020, 228, 113541, doi: 10.1016/j.ijheh.2020.113541.

[11] Babich, H. Butylated hydroxytoluene (BHT): A review. Environ. Res. 1982, 29, 1-29, doi: 10.1016/0013-9351(82)90002-0.

[12] Lanigan, R.S.; Yamarik, T.A.; Andersen, F.A. Final report on the safety assessment of BHT. Int. J. Toxicol. 2002, 21, 19-94, doi: 10.1080/10915810290096513.

[13] EFSA (European Food Safety Authority Panel on Food Additives and Nutrient Sources added to Food), 2012. Scientific Opinion on the re-evaluation of Butylated hydroxytoluene BHT (E 321) as a food additive. EFSA J. 10, 2588 [43 pp.].

[14] ECHA (European Chemicals Agency), 2010. In Evaluation of new scientific evidence concerning the restrictions contained in annex XVII to regulation (ec) No 1907/2006 (reach). Review of new available information for dibutyl phthalate (DBP).

[15] Seckin, E.; Fromme, H.; Völkel, W. Determination of total and free mono-n-butyl phthalate in human urine samples after medication of a di-n-butyl phthalate containing capsule. Toxicol. Lett. 2009, 188, 33-37, doi: 10.1016/j.toxlet.2009.03.002.

[16] EFSA, (European Food Safety Authority Panel on Food Additives and Nutrient Sources added to Food), 2005. Opinion ofthe scientific panel on food additives, flavourings, processing aids and material in contact with food (AFC) on a request from the Commission related to di-butylphthalate (DBP) for use in food contact materials. Question No. (EFSA-Q-2003-192, adopted on June 23, 2005. The EFSA J., 242, 1-17.

[17] Joint FAO/WHO Expert Committee on Food Additives (JECFA), 1984. Evaluations of the Joint FAO/WHO Expert Committee on Food Additives (JECFA): Nonanal. Available online at: https://apps.who.int/food-additives-contaminants-jecfa-database/chemical.aspx?chemID $=3890$ 